\title{
Homogeneity Assessment
}

National Cancer Institute

\section{Source}

National Cancer Institute. Homogeneity Assessment. NCI Thesaurus. Code C138992.

An assessment of the quality or state of being similar or comparable in kind or nature or

of being uniform throughout in composition or structure. 